\title{
Cultural Heritage and Antiquarian Attitude
}

Mats Burström

\begin{abstract}
The cultural heritage is not simply given by history; its content is also a matter for decision in the present. This calls for a dialogue between the heritage management and different groups in society. It is also necessary to formulate a vision of how material remains from the past can enrich the life of the citizen in general. One way to ensure that the cultural heritage touches people is to integrate it into new contexts. The realisation of these points requires a new aniquarian attitude towards the general public.
\end{abstract}

Mats Burström, National Heritage Board, Bor 5405, SE-1/4 84 Stockholm, Sweden.

Key words: antiquarian attitude, authenticity and change, cultural heritage, dialogue, general public, heritage management, integration into new contexts, policy on culture, preservation and use, vision.

Material culture has the power to inspire thought and reflection. It can waken memories that we did not know we had. This is true for the individual as well as for society in general. As individuals we turn a corner and our eyes encounter something long forgotten but still strangely familiar. The sight, the sounds, the smell - they all bring us back in time and make us remember. This is the "effect of the madeleine-biscuit" (cf. Proust 1913-27). Bearing in mind all that has happened since last time, we may very well view the past quite differently than we once did. Recalling the past almost inevitably makes us reflect on the present; the past helps us to understand ourselves.

The material past does not need to involve our personal history to be of interest. Since we all share the essential quality of being human, all human history can contribute to our understanding of ourselves. Encountering the foreign reveals the cultural load in the taken-for-granted and the supposedly universal. It puts the well-known into perspective. The ability to inspire thought and reflection - within academic research as well as everyday life - is a vital reason that material remains from the past should be preserved for the future. If material remains are lost, so are potential knowledge and insights.

Safeguarding the cultural heritage is the responsibility of each and every one (cf. SFS 1988:950, Chapter $1, \S 1$ ), but it is also the special task of the cultural heritage management. In order to do this in the best possible way, the heritage management has to address a number of crucial questions: How do we determine what the cultural heritage is and what the cultural values in present-day landscapes are? And, who are "we"? Is it a decision to be made solely by the professional antiquarians, or does the 


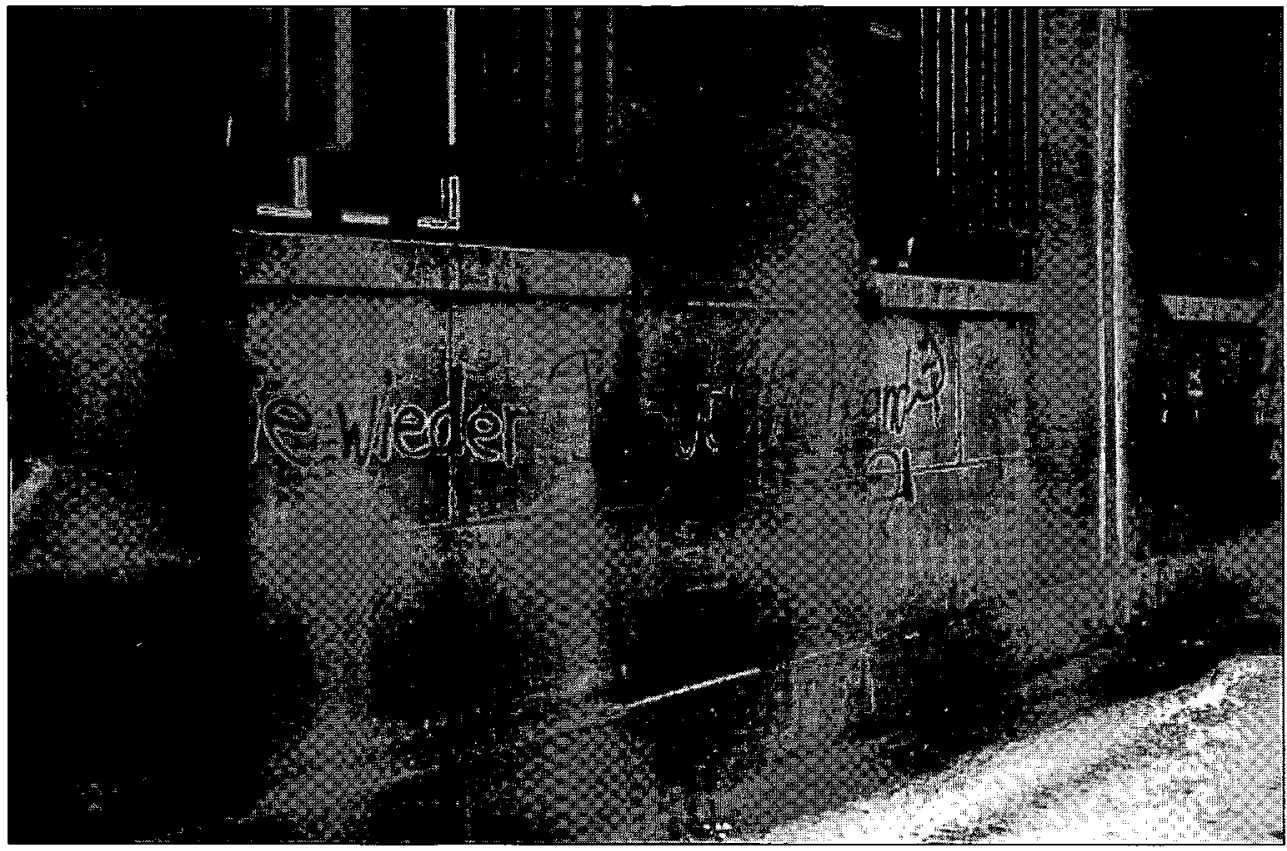

Fig. 1. The material past incites action in the present. "Nie wieder Deutssland"-graffiti on the walls of the Nazi-regime Air Ministry in Berlin. Photo: Mats Burström 1993.

citizen in general have something to say? What differences in opinion, if any, do they have? What is the antiquarian attitude towards the general public? How do we want it to be? These large issues will be briefly discussed in the following.

\section{DETERMINING THE CULTURAL HERITAGE}

The cultural heritage is not simply given by history; its content is to a great extent also a matter for decision in the present. Different groups of people have different opinions as to which objects and phenomena are interesting and worth preserving. These insights are common knowledge within heritage research as well as the political sphere. In the Swedish State policy on culture, it is declared that every time period forms its own opinion of the meaning of cultural heritage and of which parts of it have special value. It is also stated that what the cultural heritage is, is determined by cultural institutions, citizens, and society as a whole (Prop. 1996/97:3, p. 127). It is not always clear, however, how these insights and intentions are transferred into antiquarian practice.

For a long period of time the antiquarian authorities have not considered the general public as a partner in a dialogue concerning the cultural heritage and the cultural values in the landscape (cf. Burström 1999:43-45). A good heritage management, that is a management founded on scientific insights and basic democratic values, has to take into consideration the opinions of different groups in society. Instead of telling people what is interesting and worth preserving, the heritage management should invite them to a dialogue. 
Fig. 2. The times they are changing and so is the cultural heritage. The nuclear power plant in Barsebäck (Scania. Sweden) has been controversial because of the short distance to two large cities, Malmö and the Danish capital, Copenhagen. A phase-out is now being carried through and at the same time a discussion has started whether the power plant should be preserved for the future as a monument of a bygone era. Photo: Lotta Lamke 1996.

A most interesting example of such a dialogue is the Historic Environment Review conducted by English Heritage in the year 2000 (Review of policies relating to the historic environment 2000). The Review is an invitation to the public to express their views

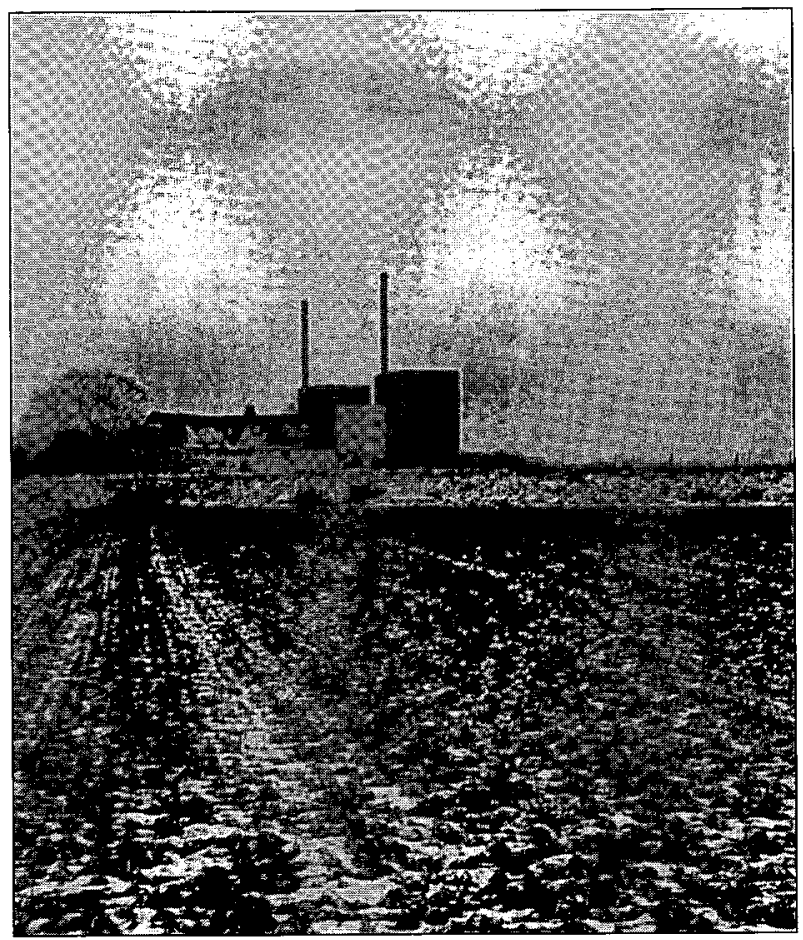
on the historic environment.

Everyone is invited to comment, but a special invitation is sent to 3500 people and organisations. They are asked questions, like: How should the historic environment evolve and adjust to new ideas and cultures over the next 25 years? How should we look after it? What uses should it be put to? What benefits should it bring? The Review puts heritage issues on the public agenda and will help to shape new government policy on the heritage.

The idea of a large-scale review is, in my opinion, excellent and well worth adopting. Irrespective of form, however, it is necessary to open up a dialogue between the heritage management and the rest of society. Otherwise there is a risk that the antiquarians form a subculture of their own and protect values that are not in correspondence with society as a whole.

Within the heritage management, the most frequently stated value of material remains from the past is their documentary value. This alludes to the possible, new knowledge about the past that can be extracted from the remains. It is, however, important to realise that material remains from the past also represent other values. They can inspire thought and reflection in a multitude of contexts that do not necessarily focus on the past itself. The cultural heritage can give insights that help to put current issues into perspective as well as give rise to reflection on eternal questions. Material remains from the past may, for example, stimulate thoughts about the passage of time, about life and death, and about ageing and decay (cf. Shanks 1998). The emotive reasons for preserving are no less important or serious than the knowledge-oriented. 


\section{USING THE CULTURAL HERITAGE}

As scholars we believe that the cultural heritage is important and can contribute to enriching the present. The very existence of a heritage management shows that we are not alone in our conviction. Society has found that the cultural heritage contains qualities that motivate the expenses of a special management. Preserving the cultural heritage is, however, not enough. In the Swedish State policy on culture it is explicitly stated that the heritage also should be used (Prop. 1996/97:3, p. 27).

Preservation and use are, of course, dependent on one another. In the antiquarian practice, however, almost all efforts seem to be directed toward preservation. In Sweden this is a result of the cultural management being focused on community planning since the early 1970s. As a matter of fact, today most ancient sites and monuments are given attention only when they are found to be in the way of a planned land development. The attention is then often focused on the costs that the sites and monuments may entail, for example, in the form of rescue excavations. When there is no threat, there is usually silence. The exception from this general pattern is the small minority of sites that are incorporated in the tourist industry.

For the heritage management, this situation is problematic. If people in general above all associate the cultural heritage with costs and potential problems, it is difficult to get an understanding of its deeper values. In the general planning undertaken by Swedish local government, areas with ancient monuments and sites are often named "danger-areas". The "danger" referred to is, of course, the costs that the archaeological remains can generate in connection with a land development. That the remains also represent a resource that can enrich people's lives and contribute to making the area attractive is very seldom discussed. If remains from the past constitute a danger, who will miss them? Words obviously have power over thought.

It would seem that the heritage management is in urgent need of a vision concerning how the cultural heritage can be used as a resource to enrich the life of the citizen in general. The management needs to take a more offensive position and make visible the values that the cultural heritage represents as well as what it can give to people, even in situations where the heritage is not threatened. It is especially important to establish and maintain a dialogue with a broad general public, including groups who today have no special relation to the officially recognised cultural heritage. This is important for democratic reasons, and it will contribute to the continuous formation of the cultural heritage.

\section{APPRECIATING NEW CONTEXTS}

Landscapes are - and have always been - in a state of change. In the present-day landscape we therefore find a cacophony of material expressions; objects and phenomena from different periods and different cultural contexts are intermingled in a seemingly haphazard way. Prehistoric sites and monuments are found side by side with historical remains and buildings covering the time up to and including the present. Rather than to try to avoid this complexity, it should be recognised as a characteristic feature of the present-day landscape and as something to which the heritage management 


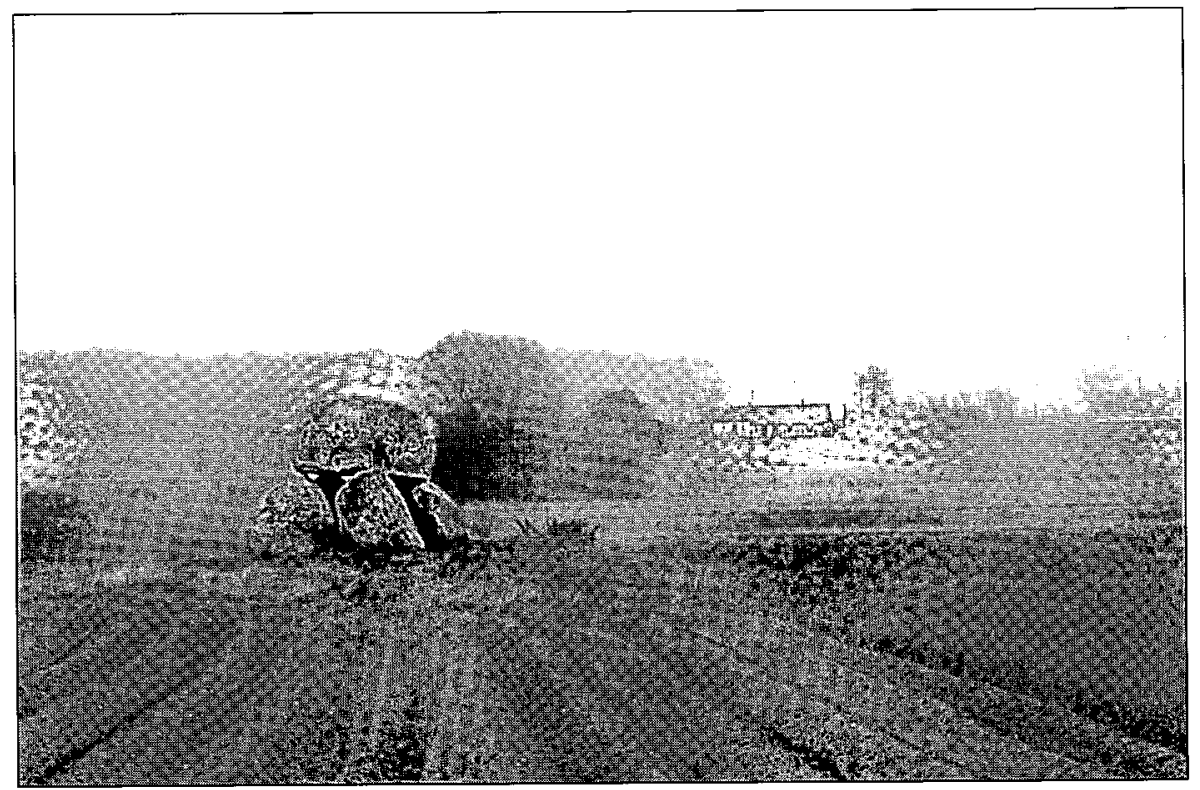

Fig. 3. A bricolage of different ages. A dolmen lying bare in a modern large-scale agrarian landscape in Hofterup (Scania. Sweden). In the distance is a traditional farmstead, and at the horizon power lines to the Barsebäck muclear power plant are dimly seen. Photo: Mats Burström 1984.

must relate.

There is, however, a distinct difference between how professional antiquarians, on the one hand, and the general public, on the other, usually regard the temporal dimension of the landscape (Burström 1999). For the antiquarians it seems natural to divide the landscape into different time horizons. The landscape is then seen as a kind of millefeuille gateau in which each stratum is a whole unto itself. An important part of the work is thus to determine to which time stratum individual objects belong.

For people in general, it is rarely the dating of an ancient monument or some other object in the landscape that is of the greatest interest. Instead it is the object itself, its position in the landscape, and what it might mean that is of the greatest interest. History helps to make the object meaningful by telling something about its origin. The content of the stories that are told changes over time, and this is in itself a part of the cultural heritage. Through the narratives, the material and the immaterial cultural heritage are inseparably united.

So instead of isolating and separating different temporal strata as a matter of routine, it seems reasonable for the cultural heritage management to affirm the complexity of the landscape and recognise the value of this. The mingling of past and present, ancient and modern, creates a bricolage of different ages that stimulates thought. It is, for example, one way to materialise the passage of time. Recognising change as something natural may also affect the way in which the heritage management considers present changes. 
Hitherto the policy of the heritage management has been to try to avoid all changes to the area surrounding ancient monuments. The Swedish law protects not only the monument itself, but also an area large enough to give the monument the "necessary space" with respect to its art and importance (SFS 1988:950, Chapter 2, § 2). In antiquarian practice this has been interpreted as a demand for some kind of authenticity. Instead of accepting that ancient monuments are incorporated in, for example, a newly built housing area, they have been excavated and removed. The logic behind this praxis is that the immediate surroundings would have changed too much for the monuments to be understandable. That is, understandable in relation to a presumed "original" context.

Integrating the cultural heritage into new contexts may, however, very well be a way to both ensure its survival and add new values to it. This will most likely increase the number of people who come in contact with the cultural heritage and who thereby get a chance to discover its qualities. So the goal should not be to avoid having the cultural heritage touched by change, but to ensure that it touches people. People's interest and devotion is probably the most important prerequisite for the long-term survival of the cultural heritage.

\section{English revised by Laura Wrang.}

This paper was originally presented at the $6^{\text {th }}$ annual meeting of the European Association of Archaeologists in Lisbon, Portugal, in September 2000.

\section{REFERENCES}

Burström, M. 1999. Focusing on time. Disciplining archaeology in Sweden. In: Gazin-Schwartz, A. \&

Holtorf, C. J. (Eds). Archaeology and Folklore. Theoretical Archaeology Group/TAG. Routledge. London \& New York. Pp. 35-47.

Proust, M. 1913-27. A la recherche de temps perdu. [In search of lost time]. Paris.

Regeringens proposition 1996/97:3. Kulturpolitik. [The government bill on cultural policy].

Review of policies relating to the historic environment. Discussion Paper 1-5. 2000. English Heritage. London.

Shanks, M. 1998. The life of an artifact in an interpretive archaeology. Fennoscandia archaeologica XV. Helsinki. Pp. 15-30.

Svensk förattningssamling (SFS) 1988:950. Lag om kulturminnen m.m. [Cultural Monuments Act]. 